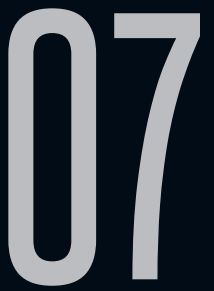

\title{
MURILO RUBIÃO E FARNESE DE ANDRADE: ESTRANHAMENTOS E SINGULARIDADES
}

Mariana Silva Franzim (UEL)

Recebido em 30 jul 2020. Aprovado em 02 set 2020.
Mariana Silva Franzim é Doutoranda em Letras pela UEL, bolsista CAPES; mestre em Letras (UEL, 2015), especialista em Ilustração (UNOPAR, 2013), graduada em Educação Artísticas - Licenciatura em Artes Visuais (UEL, 2012); integrante do projeto de pesquisa "A linguagem errante em busca da revelação: metaficção em Franz Kafka, André Breton, Rosário Fusco e Murilo Rubião", junto ao PPGL-UEL; autora de "Miniconto e abjeção: A passagem de fronteiras" (Revista Abusões, v. 7, p.97-119, 2019), "A escrita rubiana e o conto como forma: reflexões a partir de 'Marina, a intangível'" ( Literartes, v. 6, p.108-126, 2016), "O fantástico e o absurdo na obra rubiana" (GARCÍA; GAMA-KHALIL (Org.). Vertentes do Insólito Ficcional Ensaios I. 1ed.Rio de Janeiro: Dialogarts, 2015, p.368-391), “Dor, horror e crueldade no insólito ficcional: a abjeção no conto 'A causa secreta' de Machado de Assis" (MILANEZ; BRAZ; GAMA -KHALIL. (Org.). Outros corpos, espaços outros. 1ed. Vitória da Conquista: Labedisco, 2014); pesquisa centrada em Murilo Rubião e processos de criação. ORCID iD: https://orcid.org/0000-0002-5832-2761

Resumo: O presente artigo apresenta uma análise comparativa entre a obra do escritor Murilo Rubião (1916-1991) e do artista visual Farnese de Andrade (1926-1996). Observadas atentamente, a produção de 
ambos os artistas possuem ume série de afinidades, entre as quais o descompasso com as correntes vigentes em seu próprio tempo. Garantindo as diferenças entre a materialidade especifica de cada linguagem, o estudo comparativo reflete acerca do contexto histórico, da recepção crítica e dos elementos formais das produções. Por fim, a análise estabelece que as afinidades entre Rubião e Farnese se dão através da singularidade de suas obras, relacionada ao manejo de elementos do cotidiano a fim de gerar estranhamento.

Palavras-chave: Murilo Rubião; Farnese de Andrade; Singularidade

Abstract: The article presents a comparative analysis between the work of the writer Murilo Rubião (19161991) and the visual artist Farnese de Andrade (19261996). Through a careful observation, the production of both artists presents a series of affinities, including the mismatch with current trends in their own time. The comparative study between the two productions takes into account their historical context, critical reception and formal elements while ensures the specific materiality of each language. In conclusion the analysis states that the affinities between Rubião and Farnese occur through the singularity of their works, related to the handling of everyday elements in order to generate strangeness.

Keywords: Murilo Rubião; Farnese de Andrade; Singularity

Singularidade é um termo definido como:

Qualidade do que é singular, único, só; o que é peculiar a um só indivíduo e não aos outros; Particularidade; Modo extraordinário de proceder ou de pensar; Excentricidade; Coisa, ação ou palavra singular; Extravagâncias, esquisitices. (DICIONÁRIO, 2020) 
Esse parece ser o conceito adequado para balizar a análise comparativa entre a produção de sujeitos peculiares, cujas obras apresentaram um caráter inovador e descompassado com seu próprio tempo: Murilo Rubião e Farnese de Andrade.

Murilo Rubião (1916-1991) foi um escritor mineiro que, apesar de ter produzido poesias e crônicas no início da carreira e ter deixado novelas incompletas, publicou exclusivamente livros de contos. Apesar de ter escrito durante cerca de cinquenta anos (publica seus primeiros contos em periódicos no início da década de 1940 e continua escrevendo até a sua morte), o mineiro é conhecido pela sua incomum reescrita constante e sua obra completa é composta por apenas 33 contos curtos. Rubião enfrentou resistência no início da carreira do mercado editorial e da crítica especializada que encontraram dificuldade em definir o caráter de sua obra.

O autor ganhou prêmios em 1948 e 1975 pela sua obra e tem livros traduzidos para diversas línguas. Perto da morte, Rubião celebrou uma maior popularidade notada pela produção de adaptações de sua obra para o cinema e teatro e pelo surgimento de pesquisas acadêmicas sobre a mesma. Cinco dias após sua morte foi inaugurada uma exposição em sua homenagem.

Farnese de Andrade (1926-1996) foi um artista visual mineiro que se dedicou à diferentes linguagens tais como desenho, gravura, pintura, e à construção de inusitadas assemblages ${ }^{1}$ realizadas através da junção de diferentes objetos do cotidiano, muitas delas envoltas por resina.

1 Assemblage é uma categoria de produção em artes visuais que abrange colagens/ montagens realizadas através do acúmulo de objetos de natureza distintas, gerando construções tridimensionais. 


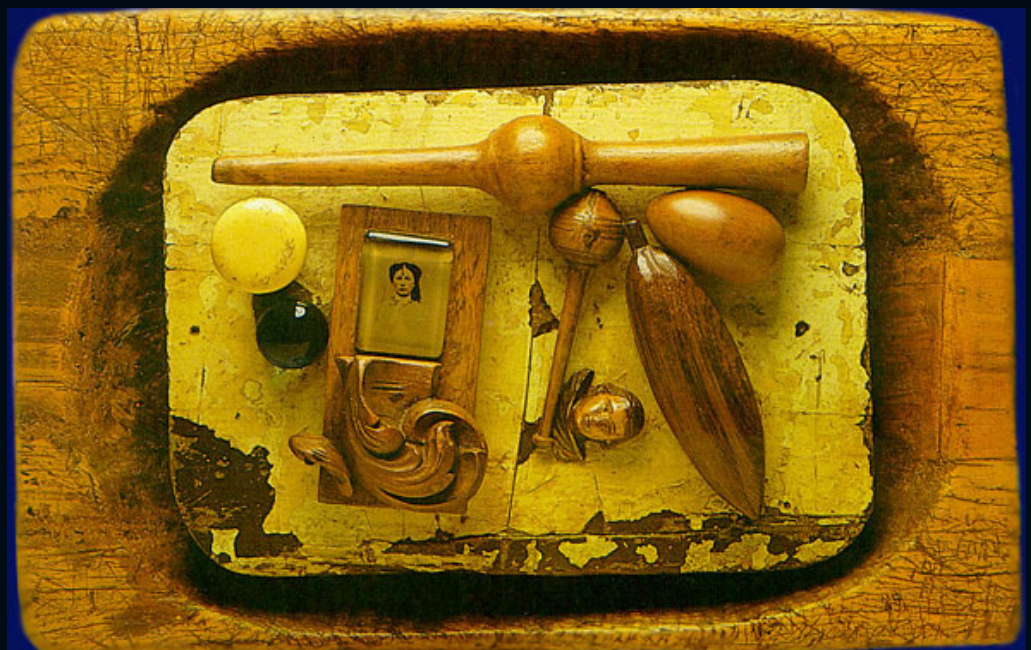

Figura 1 - Farnese de Andrade - Natureza-Morta, 1982 - gamela e objetos diversos, $20 \times 35 \mathrm{~cm}$.

Fonte: Reprodução Fotográfica Romulo Fialdini. In https://d3swacfcujrr1g. cloudfront.net/img/uploads/2000/01/000816008013.jpg Acesso em: 15.Abr.2020

Farnese, pouco conhecido pela crítica, não obteve reconhecimento do grande público em vida, mesmo tendo participado de inúmeras e importantes exposições em diversas regiões do mundo e ter recibo prêmios ao longo de toda a sua carreira. Seu trabalho ganhou popularidade postumamente, no início dos anos 2000 devido à aquisição de obras do artista pelo crítico e curador Tadeu Chiarelli para o Museu de Arte Moderna de São Paulo, às publicações da editora Cosac Naify organizadas por Rodrigo Naves (2002) e Charles Cosac (2005) e às exposições realizadas pelo Centro Cultural do Banco do Brasil.

Um olhar rápido para a biografia de Rubião e Farnese já nos permite realizar algumas aproximações. O escritor e o artista visual possuem origem mineira (Farnese nasceu em Araguari e Rubião em Silvestre Ferraz, hoje Carmo de Minas), pertenceram 
à mesma geração, sendo Rubião apenas 10 anos mais velho que Farnese. Por períodos nem sempre correlatos, residiram em Belo Horizonte, Rio de Janeiro e Espanha (Rubião em Madri durante a década de 1950 e Farnese em Barcelona durante a década de 1970). Ambos sofreram de doenças ligadas ao trato respiratório. Farnese, que já havia lutado contra tuberculose quando jovem, morreu por conta de um enfisema pulmonar, enquanto Rubião lutou contra um câncer na laringe.

Para além das coincidências biográficas, nos dedicaremos a investigar os paralelismos entre suas obras pela via do estranhamento e da singularidade das mesmas. O presente estudo não visa situar a obra de Farnese como uma configuração visual, ou ilustração, da obra rubiana; assim como não pretendemos encaixar a escrita de Rubião como uma narrativa paralela às imagens de Farnese. A nossa investigação visa ressaltar a singularidade existente em ambas as obras. Ao refletir acerca da obra de Farnese, estabelecemos uma análise crítica de importantes pontos da obra rubiana.

Encontramos paralelos na relação que Farnese de Andrade e Murilo Rubião estabeleceram com a sua própria obra. Ambos se distanciaram de relações afetivas, tendo cultivado a solidão em benefício da produção artística. Também é evidente o peso da narrativa bíblica, a apropriação de elementos do cotidiano (no caso do primeiro, objetos, no segundo, a linguagem), a incompreensão da crítica e a constatação de que teriam obtido um maior destaque caso tivessem produzido fora do Brasil. Vejamos relatos da crítica e do próprios artistas acerca dessas questões. 
Cosac $(2005$, p.45) escreveu sobre a solidão de Farnese: "Imaculado Farnese - nasceu e morreu como todos nós: só. Passou grande parte da sua vida em profunda solidão espiritual" Rubião, de maneira correlata, também cultivou a solidão: "como na infância, a solidão parece algo a ser preservado. Principalmente dos chatos. Às vezes a solidão incomoda. Mas no geral ele a percebe "como algo bom, rico'" (CHRISTUS, 1987, p.9). A lucidez e um aparente ceticismo, mesmo quando se encontravam próximos à morte, também é percebido na fala dos dois mineiros. Sobre a morte de Farnese, Cosac $(2005$, p.45) relatou:

Em 1996, Farnese morreu de enfisema pulmonar e de tristeza [...] Duas semanas antes de sua morte, ele disse: 'Vou morrer e você não vai se assustar'. De fato não me assustei, nada mudou. Só que, diante de sua obra, há quase oito anos me pergunto: quem está morto?

Em sua última entrevista, cedida alguns dias antes da sua morte, Rubião (In: KAUFFANN et al., 1991) declarou:

Não, não tenho medo da morte. Até receberei ela bem. Às vezes me preocupo um pouco com os problemas que eu vou causar: enterro, missa de sétimo dia, que a família não vai dispensar convite de jornal... O resto vai ser muito simples, nem me preocupo com o terno que eles vão escolher para a viagem [...] Eu vou ter certa surpresa se tiver vida após a morte. Eu não acredito muito em vida após a morte, não. Eternidade... Você imagina se o negócio for eterno... É o castigo. Eu tenho uma das epígrafes... "naquele dia...", eu não me lembro de cor, mas, que os homens vão desejar morrer e não conseguirão ("E naqueles dias os homens/Buscarão a morte e não a acharão/Desejarão morrer e a morte/Fugirá deles "Apocalipse, 9, 6- epígrafe do conto "Os Comensais"). 
Farnese foi incompreendido pela crítica de seu tempo: "Exceto os ensaios verdadeiramente inteligentes do crítico Jayme Mauricio, também já falecido, seu relato visual nunca chegou a causar impacto nos círculos de artes visuais vigentes" (COSAC, 2005, p.45). Rubião também não foi bem aceito inicialmente pela crítica:

Alguns críticos compreenderam, mas a maioria não teve muita sensibilidade. Quando saiu o primeiro livro, o Ex-Mágico, todo mundo achava meu trabalho um negócio muito estranho. Falouse muito, publicaram muita coisa, mas a crítica não entendeu bem (MARINO, 1989, p.3)

Cosac supõe que a dificuldade crítica e a baixa popularidade de Farnese tenham mais a ver com o contexto cultural brasileiro da época do que com a qualidade e relevância da obra em si:

Há os que dizem que ele teria sido mais reconhecido na Alemanha, talvez por ser um país luterano onde seu imaginário cristão invertido não incomodasse tanto. Mas, caso ele tivesse nascido na Alemanha, não teria construído a obra que construiu (COSAC, 2005, p.45)

Percebemos um julgamento parecido acerca da produção rubiana. No período em que residiu nos Estados Unidos, Fernando Sabino insistia através de cartas para que Rubião aprendesse inglês e cogitasse uma mudança: "Tenho certeza de que publicados aqui, seus contos fariam tremendamente mais sucesso que no Brasil, onde infelizmente nossa literatura ainda está com vinte anos de atraso" (SABINO, Apud CABRAL, 2016, p.261). Sabino considerava que o problema da recepção da obra rubiana se dava por conta da situação da cultural brasileira do período: 
Continuo achando, pelo que tenho lido, que seu livro ainda não encontrou a espécie de repercussão que deveria ter caso houvesse no Brasil menos burrice e mais honestidade, - com exceção, como disse, do artigo do Pagé, cuja carta achei até melhor, pois mais direta, franca e pessoal. Fora dele estão apenas repisando com muita simpatia uns lugares comuns que nós já esperávamos - inclusive Kafka e tudo mais (SABINO, Apud CABRAL, 2016, p.272)

O descompasso entre a obra de Rubião e os gêneros ou modos literários em voga é correlato a inadequação de Farnese às correntes estéticas vigentes:

A obra desenvolvida por Farnese de Andrade não pertenceu, tampouco gerou, um estilo, uma escola ou um movimento. Esse fato não a posiciona acima ou abaixo de seus contemporâneos, mas denuncia sua singularidade, como também a dificuldade em contextualizá-la conforme a historiografia vigente das artes visuais (COSAC, 2005, p.9)

A obra rubiana também habitou esse não-lugar. Por não se enquadrar às correntes literárias em voga no seu tempo encontrou obstáculos para produzir e publicar desde o início de sua carreira:

Um quarto de século antes de Júlio Cortazar e Gabriel García Márquez popularizarem o realismo mágico, era fatal que houvesse reações de estranheza [...] Publicava suas aventuras no jornal onde trabalhava, a Folha de Minas. Certo dia, deparou com um fecho que não era seu, acrescentado pelo editor da página literária: 'Nesse momento, eu acordava'. Justificativa do autor da emenda: 'Você acha que alguém ia acreditar nisso?' Era através das crônicas na Folha de Minas que Murilo exercitava a mão (WERNECK, 1986) 
O escritor conseguiu publicar seu primeiro livro em 1947 após diversas recusas e viu um aumento de interesse sobre a sua produção literária a partir da década de 1970:

Em meados da década de 70, o destino do escritor mineiro Murilo Rubião parecia decidido. À beira dos 60 anos, tudo fazia crer que ele ficaria sendo um desses autores que a crítica põe nas alturas mas que, para o leitor comum, simplesmente não existem [...] Para o grande público, Murilo Rubião realmente não existia - e nem mesmo a fantasia que embebe seus contos deixava imaginar que ele chegaria como best-seller aos 70 anos [...] O Convidado, uma das três coletâneas de histórias atualmente disponíveis, já vendeu 10 mil cópias. A Casa do Girassol Vermelho atingiu as 12 mil; e na semana passada a Editora Ática, de São Paulo, começou a distribuir a 11a edição de $O$ Pirotécnico Zacarias, que totaliza agora a marca nada desprezível dos 100 mil exemplares. (WERNECK, 1986)

Rubião antecipou, em décadas, as vertentes literárias latinoamericanas ligadas à estética do insólito. Apesar no seu pioneirismo, não é seguro afirmar que Rubião tenha fundado escola. Os contos rubianos tem sido aproximados pela crítica ao realismo mágico latino-americano, porém sua poética é de uma outra ordem: "Júlio Assis e Harildo Ferreira chamam o autor de pai do gênero 'realismo mágico' na América Hispânica. Murilo Rubião diz que o escritor (ele mesmo) nasceu pela poesia" (NUNES, 2012). Sobre a aproximação com estas correntes, o próprio Rubião se posicionou em diversos momentos: "Eu não faço realismo fantástico no sentido dos autores latino-americanos. A minha literatura é bem diferente" (SEBASTIÃO, 1988). Se é possível afirmar que ele tenha 
sido precursor de alguma corrente, acredito estar mais próximo da literatura praticada por autores contemporâneos tais como Nuno Ramos e Veronica Stigger, autores que compartilham com o Rubião uma prosa com caráter poético, abjeta (pois mostra mais do que narra), incômoda e enigmática (pois repleta de vazios).

Rubião foi singular em seu próprio tempo e ainda permanece singular. Desde a preparação para a publicação de $O$ Ex-Mágico (1947), sua primeira coletânea de contos, se instaurou a comparação entre o escritor mineiro e Franz Kafka. O primeiro veredito foi feito por Mario de Andrade, em carta de 1943, na qual analisou os contos que compuseram a já referenciada publicação. A partir daí seguiu-se uma série de análises críticas investidas nessa aproximação, dentre as quais podemos citar as de Álvaro Lins (1948), Nelly Novaes Coelho (1996), Davi Arrigucci Jr (1998) e tentativas de análise do próprio Rubião em uma série de entrevistas. O ponto comum nas comparações entre a obra do mineiro e do tcheco é que, apesar das proximidades, há sempre um descompasso entre ambas, sempre sobra algo que não se ajusta e que não permite o pleno enquadramento da dupla em um mesmo gênero, uma mesma espécie de literatura. Mesmo quando comparado a Kafka, a singularidade rubiana salta aos olhos.

No artigo "Biblical Correspondences and Eschatological Questioning in the Metafiction of Murilo Rubião" (1988) publicado na revista World Literature Today da Universidade de Oklahoma, Robert DiAntonio analisou os contos O Ex-Mágico da Taberna Minhota (1947) e O Pirotécnico Zacarias (1974). O artigo destaca que o interesse internacional pela literatura brasileira esteve comumente relacionado a obras que possuíam conteúdo com viés sócio político, e 
que porém, Murilo Rubião, distanciado dessa vertente, foi um escritor singular, com uma produção consistente, tendo criado, já com seus primeiros contos da década de 1940, uma tradição pessoal de difícil definição. Segundo o crítico, Rubião possuiu um foco estético único relacionado à metaficção, semelhante a autores como John Barth, Franz Kafka e Jorge Luis Borges, porém ricamente balizado por visões e questões próprias. O autor aponta que a maioria das discussões acerca da obra rubiana tem destacado suas qualidades surrealistas ou real maravilhosas, suas visões fantásticas e ambientes mágicos, porém, raramente encontra análises dedicadas à unidade temática e à lógica onírica subjacente da sua ficção.

O descompasso do projeto poético de Rubião com seu próprio tempo pode ser atestado, além da resistência da crítica, através da dificuldade encontrada pelo autor para publicar seu primeiro livro. Começou a escrever poesia aos 15 anos, aos 19 escreveu seu primeiro conto. Após ter publicado diversos contos esparsos em periódicos, Rubião organizou no final da década de 1930 uma coletânea de contos intitulada Elvira e outros mistérios, mas não encontra nenhuma editora que aceitasse publicá-la. O mineiro então rescreveu e reorganizou sua seleção de contos e conclui a versão final do seu primeiro livro publicado, O Ex-Mágico, em 1940 mas só conseguiu um editor em 1946, fazendo com que a obra fosse lançada no ano seguinte, ou seja, sete anos após a finalização da edição. A sua primeira publicação é enfim lançada através da intervenção de Marques Rebelo e de financiamento do próprio escritor para bancar parte da tiragem inicial:

Até conseguir publicá-lo colecionou recusas de seis editoras. Financiou 500 dos 2 mil exemplares 
da edição e comprou mais 1 mil para distribuir. Ele guarda lembrança muito viva de sua estreia: saiu procurando os amigos, para autografar o livro, e dormiu com $O$ Ex-Mágico debaixo do travesseiro (WERNECK, 1986)

A dificuldade em encontrar um editor talvez possa ser compreendida pelo descompasso entre a escrita de Rubião e o cenário literário brasileiro no período. Acreditamos que olhar para a obra de outro artista deslocado, nesse caso Farnese, nos permite enfatizar a singularidade da escrita rubiana que nos lançam numa perspectiva diferente daquela frequentemente adotada pela crítica.

A resistência inicial do mercado editorial e da crítica indicam que o projeto poético de Rubião se encontrava deslocado do momento em que foi produzido. Cosac destacou que os artistas nascidos na geração de Rubião e de Farnese começaram a obter exposição entre as décadas de 1940 e 1960, mesmo período em que ocorreu o tardio interesse brasileiro pela arte concreta. Cosac situou Farnese em um polo oposto ao do concretismo brasileiro representado por nomes como Amílcar de Castro. Apesar de compartilharem a origem mineira e terem estudado em períodos próximos na escola de Guinard, ontologicamente e formalmente suas obras são diversas. Os objetos de Farnese possuem intensa carga autobiográfica e transfiguram "sua dor, sua solidão, seus rancores, seus complexos, suas depressões, suas relações, sua libido, seus recalques" (COSAC, 2005, p.11). Para o crítico, a condição pictórica da obra de Farnese pode ser definida enquanto "resultados de hábitos estranhos, hábitos estranhíssimos" (COSAC, 2005, p.11-13). Cosac também apresentou a dificuldade de categorizar a obra de Farnese dentro das correntes históricas artísticas: 
Poderia classificar a sua obra, num primeiro plano, como simbolista e, num segundo, como surrealista, mas ele sequer era nascido no irromper desses movimentos. Ademais, não seria verossímil. Em momento algum Farnese se curvou aos postulados do simbolismo, tampouco aos do surrealismo, mesmo que haja traços similares entre sua obra e esses movimentos. Sua única preocupação era a de continuar a trabalhar. (COSAC, 2005, p.15)

Percebemos uma postura correlata em Rubião, ao manter a autonomia de seu projeto poético independente das demandas de mercado ou das tendências estéticas em voga: "Para Rubião, as outras artes também influenciam a literatura, tanto quanto são influenciadas por ela. Ele não faz nenhum paralelo com sua obra, mas cita o surrealismo como um exemplo" (NUNES, 2012). O surrealismo aparece empregado como adjetivo, como característica das obras, talvez por falta de adjetivo melhor, por falta de um conceito que dê conta. Ao apontar o surrealismo na obra dos mineiros não faz sentido entender que praticassem uma vertente tardia e abrasileirada do movimento da vanguarda europeia.

Tanto os contos quanto os relatos de Rubião demonstram um grande compromisso com o que produzia: "O escritor não separa a vida da literatura, vida e literatura são uma coisa só" (SEBASTIÃO, 1988). Já com idade avançada, afirmou que "Até agora a literatura foi para mim um jogo, que eu joguei sério, mas se perdesse não haveria problema. Fiz o melhor que pude, mas isso não é suficiente, é preciso ter sorte e uma vocação" (NUNES, 2012).

O compromisso com o próprio projeto poético alinhado a um distanciamento das correntes em voga torna explícita a originalidade da produção tanto de Murilo, quanto de Farnese. Ao 
pensar na questão da originalidade é interessante escutar o que os próprios artistas tem a nos dizer. Farnese (In: COSAC, 2005, p.179, grifo do autor) relata que

$\mathrm{Na}$ infância, levei uma queda que me deixou amnésico por uma semana [...] Esse acidente deixou-me com sequelas neurológicas, e hoje não consigo reter o que leio ou o que vejo. Assim, nunca me interessei em folhear livros sobre arte museológica ou estar em dia com o que está se fazendo lá fora. Essa mesma deficiência que me impediu até de aprender operações básicas de matemática ou regras de português [...] trouxeme a vantagem de sair de dentro de mim tudo o que fiz, o que não quer dizer que me considere um 'original', um fora de série. Nada há de novo sob o sol, e tudo continua sempre.

Um entendimento da produção do novo como repetição e reelaboração do que já está posto também aparece no relato rubiano. O escritor defendia que tudo aquilo que escrevia era um recontar de história mais antigas. Para ele, todas as histórias que poderiam ser escritas já apareciam de alguma forma na Bíblia. Jorge Schwarz (In: WERNECK, 1986) demonstrou que Rubião "'usa a Bíblia como uma espécie de grande livro inspirador'. O escritor confirma: 'Toda a experiência humana está na Bíblia'”.

A singularidade do projeto rubiano não se dá por conta da inovação absoluta, sua revolução se situa não através de um movimento disruptivo, mas como uma outra possibilidade de reelaboração da tradição:

Toda literatura é marcada por um desejo de marcar seu espaço, delimitar, portanto, um território ficcional, entrando em diálogo com outros textos. 
No caso de Murilo Rubião, é de se notar que a sua literatura, ao procurar encontrar um 'tom', a sua marca, procura filiar-se e distanciar-se simultaneamente do que poderíamos chamar de uma tradição (ALENCAR, 2002)

Rubião assume um papel ambíguo em relação à tradição. O escritor não nega as marcas do legado literário na sua escrita, mas percebe a necessidade de se desvencilhar de determinadas convenções. Alencar (2002) aponta que o contista "acaba revelando o que recriminara nos escritores mineiros na década de 40 , ao falar da mania que tinham, e ele também, de viver entre montanhas, alimentando-se de seu próprio eco" (ALENCAR, 2002). A forma criada por Rubião para engendrar a singularidade de sua própria escrita não se dá através da negação total da tradição, mas por uma espécie de desmonte da mesma, o que pode ser observado na análise de Nunes (2012): “O escritor afirma que sua influência maior veio de Machado de Assis, e acreditamos que sua obra possa ser o produto da 'desleitura' dos textos deste".

DiAntonio (1988, p.62, grifo nosso), ao apontar a singularidade como característica da literatura de Rubião, determina que

one very singular writer, Murilo Rubiao, has maintained a consistent tradition of undefinable personalism in his short fiction since the 1940s. His is a unique esthetic focus, related to the 'metafictions' of Barth, Kafka, and Borges, but still richly framed in the writer's personal vision and concerns. It is generally the case that most discussions of Rubião's works underscore the surrealistic or magically realistic qualities of his writings. His fantastic visions and magical worlds are usually alluded to and described, but very 
rarely is there an attempt to analyze the underlying oneiric logic and thematic unity in his fiction.

A singularidade resultante da unidade temática e da lógica onírica, tal como apontadas por DiAntonio, pode ser definida como um dos principais pontos de contato entre Rubião e Farnese. Apesar da proximidade geracional e da origem mineira, é um dado óbvio que os objetos produzidos por ambos, ou seja, o resultado formal de suas ações poéticas, é bem diverso. $\mathrm{O}$ que os aproximaria seria a maneira pela qual lidaram com a própria obra e com o ofício de ser artista e que resultou em trabalhos singulares. Com base nisso estabeleceremos agora uma análise comparativa das matériasprimas e procedimentos utilizados pelos artistas.

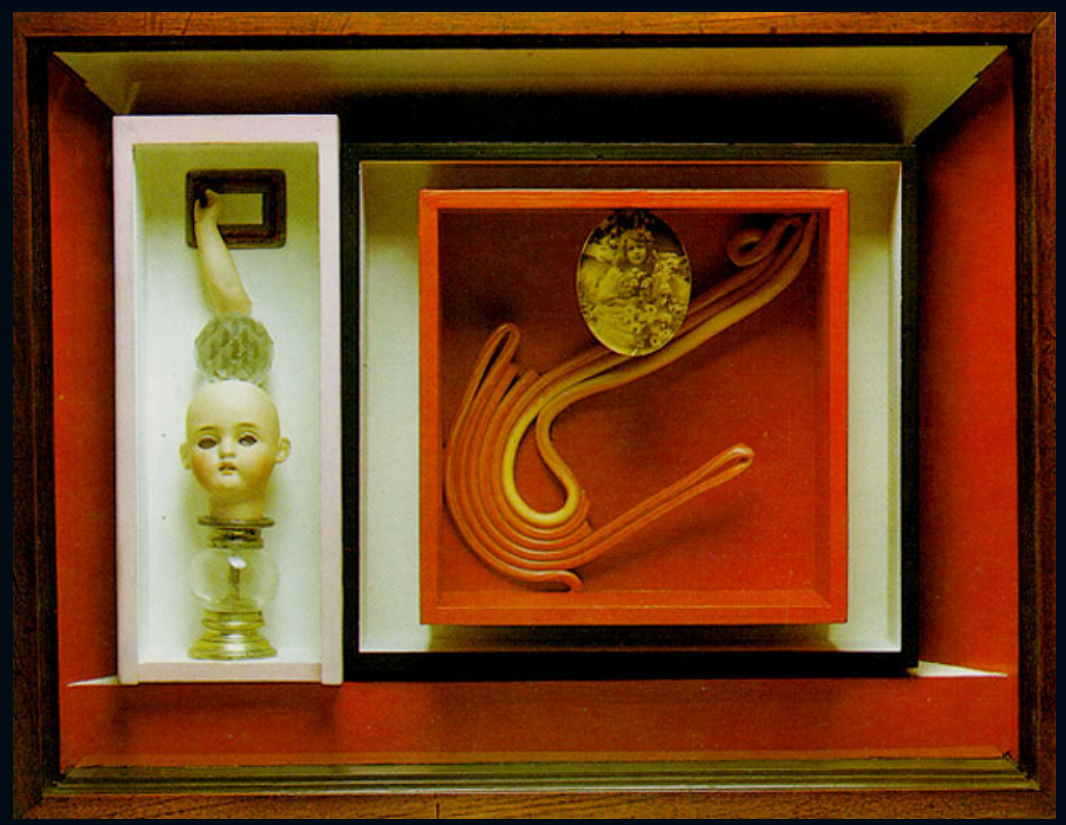

Figura 2 - Farnese de Andrade - Composição em Vermelho, 1972-74, 57 x 44cm.

Fonte: Reprodução Fotográfica Romulo Fialdini. In https://d3swacfcujrr1g. cloudfront.net/img/uploads/2000/01/000816007013.jpg Acesso em: 16.Abr.2020 
Farnese de Andrade inicia sua carreira como gravador. Tudo muda quando, ao coletar pedaços de madeira na praia, recolhe outros objetos e materiais descartados e os transforma em assemblages. 0 artista relata o momento da descoberta da nova linguagem:

Comecei a percorrer a Praia de Botafogo (na época [início da década de 1960], um maravilhoso receptáculo de lixo) e a procurar formas de madeira e principalmente de borracha maleável, por exemplo, restos de sandálias japonesas [...] Aos poucos comecei a recolher também madeiras belamente tratadas pelo sol, pelo sal e pelo mar, assim como cabeças de bonecas de plástico ou de borracha com aquelas marcas da passagem do tempo, com aspecto de coisa usada, desgastada, machucada, vivida. Pelo costume automático de lixar, também tive gosto em tratar com diversas lixas os contornos de madeira já feitos pelo acaso, ressaltando apenas, polindo o trabalho da natureza. Um dia, a base de um possível móvel em estilo antigo, um ovo de madeira daqueles de costura, uma cabeça de santo de gesso e uma bola de gude se juntaram e 'aconteceu' o meu primeiro objeto. (FARNESE In: COSAC, 2005, p.181)

É curioso o relato da criação pois aqui o artista se coloca como mera testemunha. Os objetos se tornam sujeitos da ação e o encontro (supostamente) fortuito entre eles engendra sua própria criação enquanto novo corpo, enquanto obra. Ao artista só cabe se surpreender, se maravilhar e se submeter. Seduzido pela criação de obras tridimensionais, Farnese deixa de lado a gravura e passa a se dedicar intensamente à criação de objetos:

Nessa época [c. de 1969], já estava percorrendo os bricabraques do centro da cidade, os depósitos de 
material de demolição, os cemitérios de navios e até antiquários, quando passei a me interessar pelos oratórios rústicos e pelas caixas antigas, fechadas, misteriosas. A estas chamei de Em busca do tempo - não o tempo perdido de Proust, mas o que não existe, que as fotos tentam colher e imobilizar. Tive um tio fotógrafo que, para minha alegria, deixou uma colação de chapas e cópias de casamento de senhores e senhoras graves e endomingados, gente que povoava há mais de sessenta anos 0 Triângulo Mineiro. Usei e ainda uso essas fotos, somadas a outras encontradas ao acaso aqui ou nos esplêndidos bricabraques de Barcelona. Preservoas entre duas camadas de poliéster transparente, que, no possível, as eternizam, pois - dizem - onde não entra ar não há decomposição. Esse processo é consequência da técnica que há um ano idealizei para realizar meus trabalhos com resina sintética. (FARNESE In: COSAC, 2005, p.183)

A partir desse relato podemos elencar as principais matériasprimas de Farnese: fotografias antigas e objetos descartados das mais variadas naturezas organizados em um ambiente confinado: caixas antigas, oratórios ou envoltos em resina. Entre esses elementos recorrentes, podemos destacar a força simbólica dos oratórios:

Os oratórios eram, e talvez ainda sejam, comuns às residências mineiras. Neles deixamos nosso desespero, nossas súplicas, nossos pedidos de perdão, acendemos velas, colocamos santos ou um crucifixo, fazemos promessas e juramos lealdade eterna a Nosso Pai. Há neles o mesmo anonimato das tábuas de corte e das mesas de açougue, adicionados aos mistérios divinos e segredos íntimos; pois em vez de sangue, neles foram derramadas lágrimas [...] Os oratórios contêm portas e isso automaticamente vela a obra [...] 
Penso que, além de mais um não ao seu passado, o objeto fechado, mais precisamente o oratório embevecido pela sua conotação cristã como uma minicapela portátil, também causa ao espectador um elemento surpresa que na 'obra aberta' é restrito à sensação de impacto. Um aspecto característico do objeto fechado é a interação com o outro. Para vê-lo, temos que abri-lo, tocálo. Por menos táteis e convidativos que sejam seus conteúdos, os oratórios forçosamente interagem com o público. Dentro, uma grande surpresa ou uma grande alegria, pois há uma ironia sardônica que permeia quase toda a obra de Farnese. (COSAC, 2005, p.41)

O formato do oratório apresenta uma correlação com o formato do livro. É preciso abrir o livro para acessar seu conteúdo assim como abrimos as portas do oratório. Eles são objetos pequenos, do uso íntimo pessoal, trazidos para perto do corpo. Possuem dimensões reduzidas que encerram um universo simbólico e narrativo imenso. Há uma relação dialógica intensa entre o usuário de um livro e o usuário de um oratório. Aquele que lê um livro silencia e escuta, movimento contrário de quem se coloca frente ao oratório. Nesse último, o objeto é silenciado e quem fala incessantemente é o sujeito. O santo de devoção devolve apenas sua cegueira e seu mutismo. Nós olhamos para o livro e olhamos para o oratório mas eles não nos olham de volta. Temos a ilusão de adentrar um mundo que na verdade é hermético e que nos encerra no lado de fora.

Relacionado à clausura das composições de Farnese, podemos destacar mais um elemento. A utilização da resina é um ponto chave da sua poética. Segundo Cosac (2005, p.31) 
As resinas estavam para Farnese como o pincel e a tinta estariam, grosso modo, para o pintor [...] Suas primeiras tentativas de trabalho com a resina foram frustradas, pois o tom amarelado dificultava a obtenção da transparência necessária à simulação de um fundo de mar ou de água doce [...] Certamente a resina foi um dos momentos áureos na trajetória do artista.

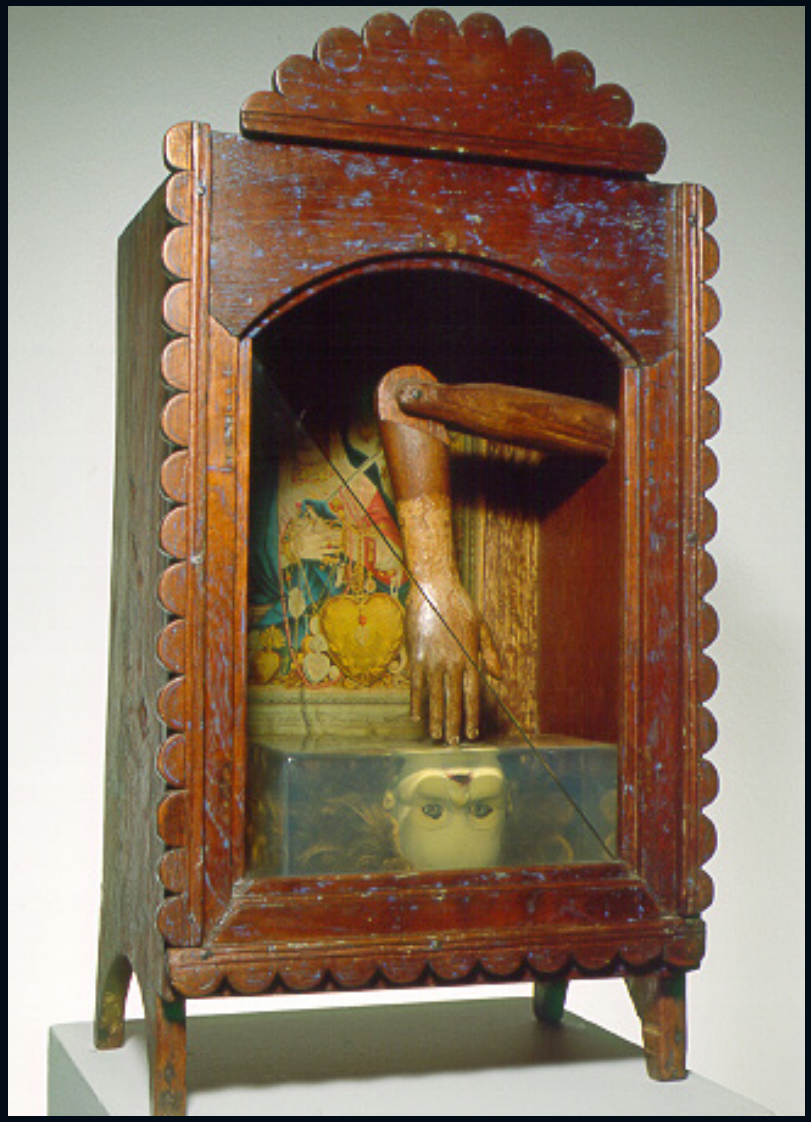

Figura 3 - Farnese de Andrade - Ofélia, 1985, braço articulável de madeira, cabeça de boneca, caixa de plástico, impressão sobre papel de imagem sacra, oratório de madeira e vidro, 87,5 x 46,5cm. Fonte: Acervo MAM-SP. In https://mam.org.br/wpcontent/uploads/2016/11/1996.147.jpg Acesso em: 16.Abr.2020 
Ao analisar as obras Ofélia e Ofélia apontada, Cosac (2005, p.33) afirma: "A sensação de moção e paralisação é concomitante, mútua e eternizada pela sensação de congelamento que resulta da técnica de resina". Essa sensação de confinamento, congelamento, pausa no tempo é também comum aos contos rubianos. Esses parecem obedecer a uma lógica espaço-temporal próprias, como um simulacro em pane da nossa realidade empírica extratextual. Os personagens de Rubião são criaturas com uma existência miniaturizada, suas vidas se limitam ao recorte temporal no qual o conto se passa; não possuem profundidade, mas ao mesmo tempo não são rasos: são opacos; possuem passado, mas esse passado é inacessível para eles e para nós; não possuem futuro, eles compartilham a condição de condenados: a cela é o conto, é o eterno presente da leitura. $\mathrm{O}$ mesmo se passa com as figuras de Farnese fixadas na resina. Elas possuem passado: podemos percebê-los nas marcas materiais da passagem do tempo em suas superfícies. Farnese não trabalha com objetos industrializados novos: as bonecas, os ex-votos, os santos, as fotografias não foram produzidos para ser utilizados em uma obra de arte, eles tiveram uma vida prévia e foram sequestrados pelo artista quando já eram dejetos. Ao serem confinados a sua possibilidade de futuro é barrada. Eles vão vivenciar a imutabilidade do tempo. A resina os fixa em um lugar e posição únicos e impede o seu contato com o ar: eles não podem nem mais apodrecer. Para se deteriorarem precisariam entrar em contato com o oxigênio e isso não será mais possível: estão condenados a eterna condição de serem para sempre o mesmo.

Farnese e Rubião construíram o extraordinário através do rearranjo de elementos ordinários. Percebemos nos relatos acerca 
do processo de construção de obras, um atento olhar de Farnese ao espaço que está ao seu redor:

A importância que atribuo às gamelas é relato do própria artista, um entusiasmo dele, talvez por tê-las descoberto de maneira tão óbvia: viu a empregada batendo massa numa gamela para assar pão de queijo. Embora não tenha abandonado as gamelas como elemento de seu vocabulário, é inegável que nelas viu um suporte mais aberto, mais evidente. Os oratórios, armários, gavetas e caixas também faziam parte do imaginário mineiro. Embora a obra de Farnese tenha quase sempre sido considerada claustrofóbica e pesada, era justo que ele usasse esses elementos como ponto de partida (COSAC, 2005, p.41)

Farnese e Rubião buscaram matéria-prima para as suas obras no cotidiano. Rubião falava sobre o maravilhoso presente no dia-adia em vários relatos e colecionava recortes de jornais de notícias bizarras. Nelly Novaes Coelho (1996) utilizou a fala do próprio Kafka para tecer uma aproximação. É possível entrever na escrita rubiana o mesmo leitmotiv expresso por Kafka: o estranhamento que se esconde em situações do cotidiano:

E por detrás desse estranho cotidiano familiar, parece-nos ouvir o eco da lição de Kafka: 'Não é preciso que saias de casa. Fica assentado à mesa e escuta. Nem mesmo escutes, espera simplesmente. Nem mesmo esperes, permanece silencioso e solitário. O mundo vai oferecer-se a ti para ser desmascarado, não poderá impedir que 0 faças'. [sic] Tendo ouvido ou não a recomendação kafkiana, [...] o que Murilo Rubião tenta, ao longo de seus escritos, é justamente esse desmascaramento (COELHO, 1966) 
Rubião, de fato, deu sinais de estar a par desta afirmativa kafkiana; ele relatou:

Acho que fantasia não existe. Às vezes, a vida dá a impressão de ser absolutamente irreal e, mesmo que a normalidade está é [sic] nestes textos da chamada literatura fantástica. A literatura fantástica é muito mais normal que a vida. Esta irrealidade da vida é um dado muito concreto. De vez em quando a gente fica espantado com as coisas do cotidiano. Acontecem coisas estranhíssimas. Basta abrir um jornal e conferir (RUBIÃO, Apud SEBASTIÃO, 1988)

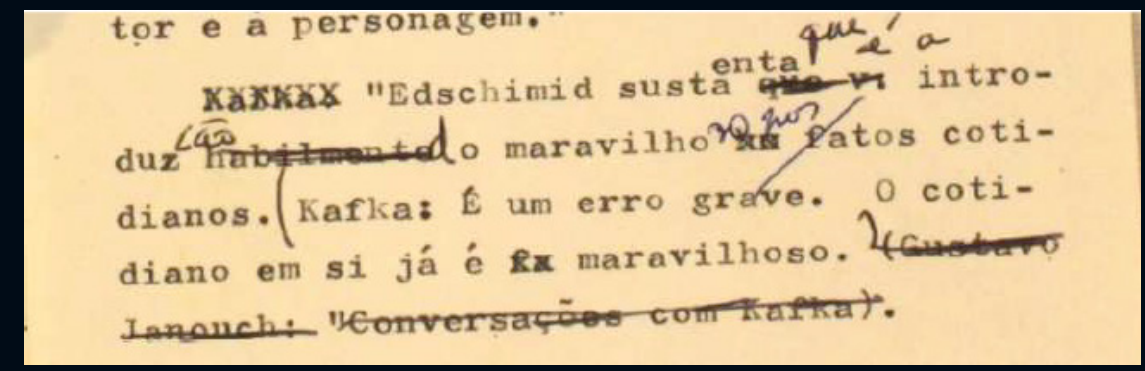

Figura 4: Nota pessoal de Murilo Rubião: Comentários sobre Franz Kafka. Fonte: Acervo dos Escritores Mineiros da Universidade Federal de Minas Gerais.

A matéria prima dos contos rubianos parece ser a mesma dos objetos de Farnese: elementos sacros, pagãos e utilitários, envoltos numa aura confessional/memorialista. Os narradores de Rubião falam das suas dores, dos seus desencontros através de uma narrativa fragmentária e confusa, assim como aquelas das memórias recalcadas, repletas de buracos e saltos. Também é possível apontar uma correlação entre a forma encontrada pelos dois mineiros para executar suas obras. Salva a distância gerada pela especificidade de cada linguagem, de certa forma os contos rubianos e os objetos de Farnese compartilham características 
tais como o tamanho reduzido, a concisão, o agrupamento de elementos díspares em um mesmo universo.

Há também um jogo entre opacidade e transparência nas obras de ambos. Rubião utilizou de uma linguagem extremamente simples e clara, aquela do cotidiano. Rubião não inventou palavras, não criou neologismos, não se apoiou em palavreados rebuscados. As orações rubianas são diretas e bem construídas. A maneira como escolheu suas palavras e as organizou em orações deixa seu texto fluído. Em uma primeira leitura é fácil se enganar e acreditar na transparência das palavras, acreditar que o signo translucido nos permita entrever um significado estável e perene. Há uma promessa e uma sedução na aparente transparência das suas palavras e sentenças. Mas essa transparência só existe na aparência, como truque para ludibriar o leitor. A forma através da qual Rubião narrou é aparentemente translúcida, mas o que ele nos conta é opaco. Não conseguimos ver através do que é narrado. Qualquer fonte de luz que nos permitiria elucidar o que está sendo contado é completamente absorvida e anulada. Ao adentrar na narrativa percebemos que há algo que resiste, algo que nos barra. Seus contos são compostos por um núcleo opaco envolto em um material translúcido. O leitor adentra o campo da aparente transparência das palavras simples, mas é barrado ao se aproximar do núcleo, rígido, opaco, impenetrável. Permanecemos no meio translúcido e gelatinoso, incapazes do nos movermos, incapazes de vislumbrar o que se passa. A despeito de serem compostos por uma falsa transparência, os contos de Rubião parecem possuir um núcleo de significado. Mas esse significado é sempre um mistério, está sempre oculto, sempre intangível. 
Essa estrutura lembra a estrutura dos aforismos e parábolas. Ele parece estar falando de algo muito simples e fundamental, mas que nós não conseguimos compreender. Ao utilizar uma linguagem simples para falar de algo misterioso e inacessível, nós nos sentimos incapazes de compreender. Sentimos a falha em nós. Os vazios que preenchem seus contos dilatam os vazios do leitor.

Os objetos de Farnese pertencem a essa mesma categoria. Temos um invólucro translúcido que circunda um núcleo opaco. Os objetos cotidianos utilizados, sejam industrializados, artesanais ou orgânicos - como os ossos de animais, não são alterados de modo a se tornarem irreconhecíveis. Não há mistério algum em relação a sua constituição. Olhamos e temos palavras para identificá-los: cabeça de boneca, gamela, ossos. O mistério reside na ação do encontro, no todo da composição. Nos colocamos a frente da obra e questionamos: o que esses objetos estão fazendo ali? Assim como palavras encadeadas que formam um texto de difícil compreensão, os objetos ordenados por Farnese formam misteriosas orações. Eles parecem dizer algo, mas esse algo é inacessível. Podemos listar com palavras o que são esses objetos separadamente, mas não conseguimos encontrar palavras que deem conta do todo ou que nomeiem o conjunto tal como ele se apresenta. As relações entre os objetos ultrapassam a sua materialidade ordinária. O extraordinário está no encontro. Seria nitidamente diferente se Farnese apresentasse esse arranjo de objetos sem o invólucro da resina. A resina aponta para a falsa transparência dos significados, separa o dentro e o fora. Nós estamos sempre fora. O significado, se é que ele existe, se encontra no núcleo inacessível do objeto. Como definir em palavras o resultado do encontro casual entre 
um guarda-chuva e uma máquina de costura em uma mesa de dissecação²? É impossível dizer.

Os contos de Rubião e as assemblages de Farnese se encontram no meio caminho entre a imagem e a narração. A obra de Rubião é composta por palavras e se firma na capacidade projetiva de suas imagens. A obra de Farnese é composta por imagens mas se funda na potencialidade narrativa que emana. É nesse meio caminho entre imagem e texto que ambas se encontram. Rubião usa o texto para construir imagens enigmáticas. Farnese usa imagens para construir narrativas inacessíveis. Conforme atestamos anteriormente, há algo que afasta a obra de Rubião e de Farnese das correntes estéticas em voga no período em que eles produziram. Esse fator, que faz com que sejam exceção, foi também o que garantiu a relevância e a consistência de suas produções.

\section{REFERÊNCIAS}

ALENCAR. João Nilson Pereira (2002). A voz rouca em arquivo silencioso. VIII Congresso Internacional ABRALIC 2002 - Mediações. Belo Horizonte: UFMG, (CD). ARRIGUCCI Jr, Davi (1998). O seqüestro da surpresa. Jornal de resenhas Folha de São Paulo, 11.Abr. In http://www.murilorubiao.com.br/criticas.aspx?id=10 Acesso em: 20.Jun.2013.

CABRAL, Cleber Araújo (2016). Mares interiores: correspondência de Murilo Rubião \& Otto Lara Resende. Belo Horizonte: Autêntica Editora: Editora UFMG. COELHO, Nelly Novaes (1996). Os dragões e .... Estado de São Paulo (Suplemento Literário), 06.Ago. In http://www.murilorubiao.com.br/criticas.aspx?id=11 Acesso em: 20.Jun.2013.

COSAC, Charles (2005). Farnese objetos. São Paulo: Cosac Naify.

2 Referência ao trecho de Os Cantos de Maldoror (1868) de Lautréamont, tomado ao pé da letra como definição do belo pelos movimentos dadaísta e surrealista, que se relaciona à criação de assemblages e construções tridimensionais através da apropriação e junção de objetos de natureza díspares com o intuito de gerar estranhamento. 
CHRISTUS, Miriam (1987). O mágico desencantado dribla o câncer e ri. Estado de São Paulo, São Paulo, 20 set. Caderno 2, p.9. 2 fls.

DIANTONIO, Robert E (1988). “Biblical Correspondences and Eschatological Questioning in the Metafiction of Murilo Rubião". World Literature Today, 62(1). Board of Regents of the University of Oklahoma, 62-66. In http://www.jstor.org/ stable/40144011 Acesso em: 14.Abr.2020.

DICIONÁRIO Priberam da Língua Portuguesa (2020). Singularidade. In https:// dicionario.priberam.org/singularidade_Acesso em: 14.Abr.2020.

KAUFFMANN, Adriana, et al. (1991) A Última Entrevista. In http://www. murilorubiao.com.br/entultima.aspx Acesso em: 07.Mai.2020.

LINS, Álvaro (1948). Os novos. Jornal de Crítica Correio da Manhã, Rio de Janeiro. 2 abr. 1948. In http://www.murilorubiao.com.br/criticas.aspx?id=12 Acesso em: 20.Jun.2013.

MARINO, Alexandre (1989). "As façanhas de um escritor mágico". Correio Brasiliense, Brasília, 27 ago. Caderno 2, p.3. 1fl. In http://www.murilorubiao. com.br/entfacanha.aspx Acesso em: 07.Mai.2020

NUNES, Sandra (2012). Biografia. In http://www.murilorubiao.com.br/vidabio. aspx Acesso em: 07.Mai.2020

SEBASTIÃO, Walter (1988). Sedutora profecia do contemporâneo. Tribuna de Minas, Belo Horizonte, 03 jul. 1fl. In http://www.murilorubiao.com.br/entsedut. aspx Acesso em: 07.Mai.2020

WERNECK, Humberto (1986). "No vigor dos 70". Revista Isto é, 26.Nov. In http://www.murilorubiao.com.br/imprensa.aspx?id=5 Acesso em: 20.Abr.2020. 